\title{
Research on the Influencing Factors of Flipped Classroom Teaching Mode in Ethnic College*
}

\author{
Jinfeng Liu \\ Gansu Normal University for Nationalities, Gansu Province, China
}

\begin{abstract}
Flipped classroom is one of the signs of a modern teaching mode that focuses on students as the independent learners, which aims at cultivating their learning abilities. Therefore, the flipped classroom teaching mode is beneficial for students' innovation ability as well as comprehensive competitiveness. However, in this process there are various factors influencing the implementation of this teaching model in ethnic colleges. In view of this, this paper analyzes the related factors influencing the application of flipped classroom teaching mode in ethnic colleges based on the characteristics of ethnic colleges, afterwards it puts forward some solutions in line with the teaching reform in ethnic colleges.
\end{abstract}

Index Terms - flipped classroom, ethnic colleges, influencing factors, coping strategies

\section{INTRODUCTION}

"Internet + education" is designed to push the deep-seated integration of technology and education through applying modern technology means in teaching practice, which is the goal of educational informatization development. As the informatization teaching environment has been formed, it is necessary to make effective use of it to reform the traditional classroom teaching structure, so as to realize the substantial improvement of the teaching quality as well as the students' comprehensive quality (Mazur, E. 1991). In addition, it is challenging for educators to effectively engage students and to ensure meaningful participation in the classroom. More and more universities proactively support teaching innovations and encourage instructors to deploy educational technologies in class in order to motivate learners and to enhance learning impact (Saeed, Yun, \& Sinnappan, 2009). If the existing traditional teaching mode could not be innovated under the informational development, the education would be outdated, and our students would not learn current information. In a similar way, in ethnic areas, the education should also keep pace with modern developments, such as the World Wide Web, and e-learning, otherwise the gap between the ethnic regions and inland, China will become larger and larger. Therefore, it is crucial to create a new teaching mode on the basis of the development of ethnic education. Thus, flipped classroom approaches have been the subject of much popular attention recently; since the inception of the term around 2011 its popularity as a Google (2019) search term has risen exponentially. Along with the effective teaching, the ability to use technical skills improves student learning; thus, it can achieve the teaching goal of cultivating students' comprehension. However, there are some limitations, such as teacher-students relationship loss as well as applicable object dislocation (Zhao, XL. 2014), which leads to the deviation in the understanding of the superiority of flipped classroom.

\section{THE CONNOTATION OF FLIPPED ClASSROOM}

In the traditional classrooms that knowledge impartation is mainly conducted through teachers' instruction. Meanwhile, knowledge internalization is completed by students though doing their homework or practicing after class. However, in the flipped classroom model, the students' exposure to initial learning content is completed before the classroom sessions through various means, often technology-based or technology-enhanced, and learner-controlled, such as instructor-provided videos (O'Neil et al. 2012), which compose the pre-class self-directed learning phase (Bishop \& Verleger 2013). Moreover, the flipped classroom is an instructional strategy that reverses the traditional learning environment by delivering instructional content, via computer-based lecture videos, and uses class time for student-centered learning (Bergmann and Sams 2012). In this way the class time is utilized for interactive sessions and solving the problems, which led the teacher to become facilitator or guide by the side. (king, A. 1993 ) Therefore, flipped classroom teaching mode is a new mode which enables students to truly participate in learning activities by utilizing information technology. Rather than merely emphasizing the memorization of concepts and facts, flipped learning promotes deep learning through active and constructive processes (Ritchhart, Church, \& Morrison, 2011), requiring instructors to embrace learner-centric rather than learning-centric strategies (Roehl, Reddy, \& Shanon, 2013). This kind of teaching mode requires students to develop their independent learning ability, cooperative learning ability, as well as self-management ability. All in all, flipped classroom teaching mode is of great significance to the strategic

\footnotetext{
* This research was sponsored by the President Fund Project of Gansu Normal University for Nationalities of China. Grant Number [GSNUXM16-15].
} 
goal of promoting innovative talent cultivation.

\section{THE IDEAS OF FLIPPED CLASSROOM}

Any teaching activities should be based on the reasonable teaching ideas. In terms of flipped classroom, Brian Gonzalez, Intel Director, described the flip classroom as one where the educators give students more freedom by flipping the process of knowledge transfer and knowledge internalization, so that students and teachers can develop groove and communication.(Gonzalez 2011) Bergmann et al. hold that effective flipped classrooms contain several common characteristics: (1) students change from passive listeners to active learners; (2) technology is often used to facilitate efforts; (3) the classroom time and the traditional homework time have reversed. Homework is carried out first, while class time is arranged flexibly to realize personalized teaching; (4) the teaching content is related to the real situation; (5) class time may be used to help students master challenging concepts or engage in advanced critical thinking and problem solving. (Bergmann 2013) Hamdan et al. proposed the four pillars of flipped classroom: (1) flexible learning environment, conducive to active learning and teaching strategies; (2) the learning culture is reversed from teacher-centered to student-centered; (3) elaborate content is designed to maximize the development of students' overall abilities; (4) professional educators can coordinate students' active learning activities and guide students' independent learning. (Hamdan, N, Mcknight, $\mathrm{P}$ et al 2013) Hurtubise et al. believe that flipped classroom puts the content of teaching before class, while teachers and students carry out more active learning strategies, such as reflection, group activities or discussions through face-to-face time in class. The core ideas of flipped classrooms include arranging pre-class learning content, formative evaluation, focusing on learning gaps and developing abilities, in which teachers play the role of instructor.(Hurtubisel, Halle, Sheridanl, et al 2015) Abeysekera \& Dawson give a relatively broad definition for flipped classroom, which includes the following three points: to move most of the teaching contents relating to transmitting information out of the classroom; enabling students to engage in active, social learning activities in class. In order to maximize the benefits of classroom learning activities, students are required to complete before and after class activities. (Abeysekera, L\& Dawson, P 2015) In a word, the idea of flipped classroom is to stimulate students' initiative and enthusiasm, focusing on cultivating students' independent abilities, thinking abilities as well as innovation abilities.

\section{TheORETICAL BASIS OF FliPPED ClassRoOM}

\section{Multiple Intelligence Theory}

Traditional education only focuses on the cultivation of students' cognitive ability, which is too one-sided and stereotyped to pay attention to the overall development of students' personality. Lee, Cheng and Liu (Lee, Cheng and Liu 2011) also define student's learning achievement as follows: "students learn from some relevant knowledge and abilities through the formal curriculum of schooling and demonstrate the learning results in the cognition, affection and skills and so on". Howard Gardner, a professor at Harvard University, put forward "multiple intelligence theory" in 1983, which indicates human intelligence is diversified. Although some students' cognitive ability is lower, they have higher intelligence in other aspects, unfortunately their non-intelligence has not been detected, nor have they been paid attention to and cultivated. The diversified development and the individualized learning which is advocated by information education coincide with the theory of multiple intelligence. Guided by the theory of multiple intelligence, it aims to develop learners' multiple intelligence in accordance with their aptitude as well as their individuality.

\section{Master Learning Theory}

In view of the theoretical basis of teaching mode construction, flipped classroom teaching mode is based on bloom's Mastery Learning Theory. The basic idea of Mastering Learning Theory is that almost all students can achieve the prescribed goal as long as they are provided with appropriate learning materials and given sufficient study time as well as appropriate help (Chen 2005). The premise is to provide learners with appropriate learning materials. In other words, learning content should be suitable for learners to learn. The second is adequate time, which means that each learner needs a different amount of time to learn, which varies from person to person. In addition, appropriate aid should be provided for learners. Scaffolding should be provided for learners according to their proximal development zone, so that learners can learn independently.

\section{Constructivism Theory}

Constructivism holds that learning is not simple knowledge transfer, but a process of knowledge construction by students themselves based on the original knowledge as well as the cooperation of subject and object. In this constructivist view of learning, students use their own existing knowledge and prior experience to help them understand the new material; in particular, they generate relationships between and among the new ideas and between the new material and information already in memory (see also Brown, Bransford, Ferrara, and Campione 1983; Wittrock 1990). Flipped classroom is the advance of knowledge transmission and the optimization of knowledge internalization brought by the teaching process reform (Ye, B. 2014). Since then, the function of the classroom, the main position of teaching has changed. It is no longer just a place where students acquire knowledge, but a place where the teacher promotes their knowledge internalization and application. 


\section{INFLUENCING FACTORS OF FLIPPED CLASSROOM}

\section{The low non-intelligence of students}

Non-intellectual factors are relative to cognitive factors. In psychology, non-intellectual factors include motivation, interest, emotion, will, character, need, goal, ambition, world outlook, etc., which are the internal influencing factors of intellectual development. Flipped classroom teaching requires students to acquire strong self-management ability, so as to ensure the effect of independent learning. At the same time, self-management is closely related to students' non-intellectual factors. However, restricted to the regional, environmental and language factors, Tibetan students' English learning interest is less strong and their learning motivation is vague, which leads to their unawareness of independent learning. Moreover, Tibetan students are weak in willpower and determination to overcome difficulties, which affects their ability to solve problems.

The weak independent learning ability of students

Independent learning is a kind of self-management learning ability, which can promote learners' autonomy and independence. Through the cultivation of independent learning ability, students can acquire lifelong learning skills. In the information age, independent learning ability mainly refers to learning with networks, where students may become more efficient in learning by means of information technology (Win 2011). Network learning is a new learning method different from traditional learning. Learners make use of a rich network of resources to assist learning. However, some factors that hinder autonomous learning, such as the inability to directly contact the teachers and teaching assistants, the fact that degree and credit certificates are typically not offered, and the fact that not all courses provide audio or video files (Willging 2009). The learning difficulties experienced by students in undergraduate courses can be attributed to the passive role played by them during traditional lectures; they advocate for active learning as a remedy (Andrews, Leonard, Colgrove, and Kalinowski 2011). Furthermore, the influence of traditional teaching modes and field-dependence cognitive style of Tibetan students learning are excessively dependent on teachers, resulting in their weak consciousness of independent learning. However, in internet-based information age, the teaching mode has changed, and a new teaching mode requires that the initiative of learning activities should be given to students instead of teachers who are only mentors and helpers. Meanwhile, the learning environment has also been reformed. Knowledge learning takes place outside the classroom, while the classroom becomes the place where knowledge is internalized and practiced. All these changes require students to become the real subject of learning, allowing students to complete learning tasks through self-research, exploration, innovation, and so on.

\section{Undeveloped learning environment construction}

For pushing the development of ethnic colleges, the government has contributed heavy investment to the full campus network coverage; the construction of multimedia classrooms; micro-classrooms; recording and broadcasting rooms; audio-visual laboratories; as well as the installation of interactive electronic whiteboards. However, there are still some problems restricting the implementation of flipped classroom, such as slow and unstable network speed; inadequate multimedia maintenance; low utilization rate of recording and broadcasting rooms and language labs. In particularly, software construction; development of online learning platforms; insufficient resource bases, which seriously lag the development of "Internet + education".

\section{Imperfect incentive mechanism}

Firstly, the evaluation system for education and teachers pays more and more attention to scientific research output, which weakens the importance of teaching. (Shi 2011) In addition, the professional teachers who have been keen on teaching for many years now have a low sense of efficacy as well as a serious psychological imbalance. Secondly, since the implementation of the flipped class needs to invest a lot of time and energy, in line with the national universities development. If there were no reasonable credentials for teaching achievements, project investment as well as teaching effect, there would be no full-time teachers devoting themselves into the teaching innovation and reform, which will seriously affect the teaching evaluation, even restrict the connotative development of the universities.

\section{The weak informatization literacy of teachers}

The creation of a flipped classrooms approach has placed new demands on teachers to transform their pedagogical practices (Kong 2013). In order to save more class time for students to internalize knowledge, it is demanded that teachers collect or make teaching videos before class as independent learning materials in flipped classroom, which requires teachers to be equipped with certain information literacy skills. However, in ethnic colleges, some teachers incline to the traditional teaching or multimedia assisted teaching methods. For a long time, traditional teaching method leads to students being spoon-fed information, instead of learning independently. Furthermore, most students lack the consciousness of time management, therefore it is difficult for them to creatively surpass themselves. (Guo 2014)

\section{Teacher is the central figure in class}

Aaron, the flipped classroom initiator, emphasized in Shanghai "magnolia" international education BBS that flipped classroom is not just about making videos, but is about effective classroom management. Therefore, the key of the efficient teaching is the successful transformation of the teacher's role. However, with the transmittal model, the professor is the central figure, the "sage on the stage," the one who has the knowledge and transmits the knowledge to the students, who simply memorize the information and later reproduce it on an exam without even thinking about it (King A. 1993). Different from it, one of the characteristics of flipped classroom is the role transformation between teachers and students, in which students become the learning subject while teachers are their mentors. Thus the main 
responsibility of teachers is no longer to impart knowledge, but to become successful classroom managers. However, in ethnic universities, the cognitive style of ethnic students is field-dependent, which leads to the students depend on the teachers excessively, so knowledge transmission still mainly relies on teachers to do.

\section{COPING STRATEGIES}

\section{Cultivate students' non-intelligence}

Under the flipped classroom mode, students are mobilized and stimulated by watching video, meanwhile their cooperative learning consciousness is cultivated. In view it, the teachers should strive to cultivate and develop the students' non-cognitive. Secondly, helping students to form a correct outlook on life and world view, so that students establish the correct learning motivation and learning goals, enabling them know why to learn, what is the goal to learn. Furthermore, a strong will enables students to face difficulties without fear, which is conducive to the development of students' ability to solve problems. Therefore, teachers also need to cultivate students' willpower to help students overcome learning difficulties.

\section{Improve students' independent learning ability}

Andrews and colleagues define active learning as when 'an instructor stops lecturing and students work on a question or task designed to help them understand a concept'. There is much support for active learning in the literature because of evidence that it leads to improved learning (Andrews et al., 2011). Nonetheless the influences of Tibetan culture and the exam-oriented education model lead to Tibetan students' thinking is more inactive. When encountering problems, they tend to ask the teacher for the answer rather than search resources to solve problems. Without thinking in depth on complex topics, most students lack critical thinking skills. Obviously, this kind of learning mode unmatched to the current information-based education mode. To cultivate the students' independent learning ability and practical ability require a new teaching mode to support. Firstly, the students should be aware of the necessity of independent learning, so that they can clearly realize the talent demand in the information age. Secondly, the students should be provided with necessary psychological counseling and guidance to gradually break the traditional stereotypes, which help them to accept this new learning mode with a positive attitude. Because online teaching and other technical resources provide language learners with the flexibility to choose learning materials that suit their personal interests and abilities, teachers should introduce flexible and resource-based learning methods to learners (McDonough 2001). It can not only cultivate students' lifelong learning ability in a long-term, but also meet the needs for the environment of the development of Internet. At the same time, it provides the teachers with information education and guidance so that they have a correct understanding of network independent learning and apply network resources to assist teaching in daily teaching activities.

\section{Improve the college environmental construction as well as the leadership}

In terms of the implementation of flipped classrooms effectively, in addition to improving hardware facilities and environmental construction, more attention should be paid to the development and construction of software environment. For those ethnic students, the trilingual learning platform as well as the abundant resources are necessary, so that it will provide students with good conditions for independent learning. Secondly, the college should put forward relevant incentive mechanism to encourage the implementation of flipped classroom teaching mode. He and Guo (He and Guo 2012) have indicated that the school administration functions to assist in the amelioration of the student's learning difficulties as well as the teacher's management problems in classroom teaching. Furthermore, Huang (Huang 2008) believes that ideally, principle leadership can enhance the teacher's performance, maintain teaching quality, and thereby, enable students to learn and grow. At the same time, the academic pioneers should take responsibility for improving teachers' informatization literacy.

\section{Reverse the teacher's dominating role}

Independently acquiring knowledge ability of Digital Native has been increased, the teachers' sense of authority will be weakened. Apart from it, whether the teachers' role can be accurately positioned directly relating to the quality of classroom teaching as well as the promotion of teaching reform. (Yu 2014) Therefore, the teachers will no longer look down upon the students with the attitude of saints instead of their partners (Cai, W. 2015), which compels the role of teachers to be reversed from traditional lecturers to students' helpers, mentors as well as classroom managers. Mao (Mao 2014) suggested that for social media to be used as effective learning tools and to assure students can afford these tools, complex efforts in designing, scaffolding, and interacting with students during the process are necessary. So the teachers should restore the leading role to the students so that they can conduct their learning initiative. Moreover, Gan, Menkhoff and Smith (Gan B., Menkhoff T. \& Smith R. 2015) discovered that interactive digital technologies offer an opportunity for both instructors and students to learn collaboratively. The professor's role is to facilitate students' interaction with the material and with each other in their knowledge-producing endeavor (King A. 1993). Only in this way can harmonious teacher-students relationship be formed, with such good relationship promoted the overall development of students.

\section{CONCLUSION}


Web-based teaching and learning approaches have been recognized as important tools to enhance the educational experience of students and their collaborative learning curve (Gan B., Menkhoff T. \& Smith R. 2015). These changes help to create a seamless learning environment in which learners can access information, communicate and share information with peers, and construct knowledge collaboratively both inside and outside the classroom (Wong, 2012; Wong\& Looi, 2011). Nonetheless, with the application of flipped classroom teaching mode in ethnic colleges, it is inevitable that some factors will influence its implement. From the students' side, they lack independent learning consciousness as well as knowledge management. Secondly, the application of flipped classroom is restricted by teachers' informatization literacy as well as the unsuccessful change of the teachers'role. Furthermore, the environment construction and the imperfect incentive mechanism also lags behind it. Therefore, the students are required to establish the consciousness of independent learning, which is conducive to the practice of independent learning ability. Meanwhile, we should develop students' non-intellect so that cultivate their interest, motivation, willpower as well as other aspects of development. Secondly, colleges should improve classroom facilities and formulate corresponding incentive mechanisms to promote the implementation of flipped classroom. Thirdly, the role of teachers should be reversed from traditional knowledge imparting to the students' assistant, thus forming a good teacher-student relationship. Only in this way can the efficient classroom which based on flipped classroom be realized.

\section{REFERENCES}

[1] Abeysekera, L\& Dawson, P. (2015). Motivation and cognitive load in the flipped classroom: Definition, rationale and a call for research. Higher education research \& development, 34(1): 1-14.

[2] Andrews, T., Leonard, M., Colgrove, C., \& Kalinowski, S. (2011) Active learning not associated with student learning in a random sample of college biology courses. Life Sciences Education, 10 (4):394-405.

[3] Bergmann, J., \& Sams, A. (2012). Flip your classroom: reach every student in every class every day. Washington, DC: International Society for Technology in Education.

[4] Bergmann, J, Overmyer, J, \& Wilie, B. (2013). The flipped class: Myths versus reality [J/OL]. The Daily Riff, http://www . the daily riff. com/articles/the flipped class conversation -689. php. Retrieved May. 20, 2019.

[5] Bishop, J. L., \& Verleger, M. A. (2013). The flipped classroom: A survey of the research. In Proceedings of 120th ASEE Annual Conference Proceedings. Atlanta, GA.

[6] Brown, A. L., J. D. Bransford, R. A. Ferrara, and J. C. (1983). Campione. Learning, remembering, and understanding. In Handbook of child psychology, 3: Cognitive development, edited by J. H. Flavell and E. M. Markman, 77-166. New York: Wiley.

[7] Cai wei. Education reform in Internet + era [N]. China education news, 2015-04-09

[8] Chen xiaoduan, Stephen Keith. (2005). Systematic Investigation and Enlightenment of Contemporary western Effective Teaching Research. Comparative Education Research, (8): 56-60.

[9] Gan B., Menkhoff T. \& Smith R., (2015) Enhancing student's learning process through interactive digital media: New opportunities for collaborative learning. Computers in Human Behavior, 51: 652-663.

[10] Gonzalez, B. Focus on Educational Change--Speech at China Education Information Summit [EB/OL]. China Education News, http://www.Jyb.Cn/AD/news /. 2011-10-09.

[11] Google. Google trends: classroom. Flipped $\quad$ From https://trends.google.com/trends/explore?q=\%2Fm\%2F0h68qds\&date=all,Retrieved May. 5, 2019.

[12] Guo pengfei. (2014). Rational Thinking on Flipped Classroom in Foreign Countries. China Information Technology Education, (15): 13-16.

[13] Hamdan, N, Mcknight, P, Mcknight, K, \& Arfstrom, K. M., (2013) A review of flipped learning [M/OL]. Pearson, http: //www. Flipped learning. Org/review. Retrieved Apr. 15, 2019.

[14] He XY \& Guo DY. (2012). The relationship between student's perception of school supports and bullying behaviors in the Junior High School in Tainan City. Journal of Education, 27:83-131.

[15] Huang CP. (2008). The impact of hierarchical system on administrative reforms. School Education, 55:48-69.

[16] Hurtubisel, Halle, Sheridanl, et al. (2015). The flipped classroom in medical education: Engaging students to build competency. medical education \& curricular development, 2 (2): 35-43.

[17] King A. (1993). From sage on the stage to guide on the side. College Teaching, 41(1):30-35.

[18] Kong SC \& Song Y. A. (2013). principle-based pedagogical design framework for developing constructivist learning in a seamless learning environment: A teacher development model for learning and teaching in digital classrooms. British Journal of Educational Technology, 44(6): E209-E212.

[19] Lee AM, Cheng CP \& Liu CC. (2011). A study of the relations between principal instructional leadership and student learning achievement in the primary school. School Administration, 75:1-20.

[20] Mao J., (2014). Social media for learning: A mixed methods study on high school student's technology affordances and perspectives. Computers in Human Behavior, 33:213-223.

[21] Mazur E., (1991). Can We Teach Computers to Teach. Computers in Physics, (1):31-37.

[22] McDonough, S. K. (2001). Way beyond drill and practice: Foreign language lab activities in support of constructivist learning. International Journal of Instructional Media, (1), 75- 81.

[23] O’Neil, K., Kelly, T., \& Bone, S. (2012). We turned learning on its ear: Flipping the developmental classroom. In T. Amiel \& B. Wilson (Eds.), Proceedings of World Conference on Educational Multimedia, Hypermedia and Telecommunications, 2752-2756.

[24] Ritchhart, R., Church, M., \& Morrison, K. (2011). Making thinking visible: how to promote engagement, understanding, and 
independence for all learners. San Francisco: Jossey-Bass.

[25] Roehl, A., Reddy, S., \& Shanon, G. (2013). The flipped classroom: an opportunity to engage millennial students through active learning strategies. Journal of Family \& Consumer Sciences, 105, 44-49.

[26] Saeed, N., Yun, N., \& Sinnappan, S. (2009). Emerging web technologies in higher education: A case of incorporating blogs, podcasts and social bookmarks in a web programming course based on students' learning styles and technology preferences. Journal of Educational Technology \& Society, 12(4), 98-109.

[27] Shi jinghuan, xu tian\& li yifei. (2011). Research on Teaching and Academic Status of Teachers in Chinese Universities -- Based on the Survey and Analysis of 44 Universities. Higher Education Research, (12): 52-66.

[28] Willging, P. A., \& Johnson, S. D. (2009). Factors that influence students' decision to drop out of online courses. Journal of Asynchronous Learning Networks, 13 (3), 115-127.

[29] Win TI. (2011). A study of affecting factors for e-course learning. Journal of Industrial Technology Education, (4): 41-48.

[30] Wong, L. H. \& Looi, C. K. (2011). What seams do we remove in mobile assisted seamless learning? A critical review of the literature. Computers and Education, 57, (4): 2364- 2381.

[31] Wong, L. H.A. (2012). learner - centric view of mobile seamless learning. British Journal of Educational Technology, 43, (1): E19-E23.

[32] Ye bo. (2014). What Flipped Classroom Subverts -- on the Value and Limit of Flipped Classroom. Course.Textbook.Teaching Method, (10): 29-33.

[33] Yu tianzhen. (2014). From "Leading Actor" to "Director": Teacher Role Transformation and Its Path in Flipped Classroom of Basic Education. Shanghai Education Research, (5): 49-52.

[34] Zhao xinglong. (2014). Knowledge Internalization Process and Teaching Mode Design in Flipped Classroom. Research on Modern Distance Education, (2): 55-60.

Jinfeng Liu was born in Lanzhou, China in 1980. She received her M.A degree in Higher Pedagogy from Lanzhou University, China in 2015.

She is currently a lecturer in Gansu Normal University for Nationalities, China. Her research interest is English Teaching Methodology.

Ms. Liu got Excellent Head Teacher Award in 2012 as well as Excellent Instructor Award of National English Competition for College Students in 2014. 